\title{
PERSON-ORGANIZATION FIT AND ORGANIZATIONAL IDENTIFICATION AS PREDICTORS OF POSITIVE AND NEGATIVE WORK-HOME INTERACTIONS
}

\author{
DOROTA MERECZ and ALEKSANDRA ANDYSZ
}

Nofer Institute of Occupational Medicine, Łódź, Poland

Department of Occupational Psychology

\begin{abstract}
Objectives: The aim of the presented research was to explore the links between complementary and supplementary dimensions of Person-Organization fit (P-O fit), organizational identification (OI) and negative $\left(\mathrm{WHI}^{-}\right)$versus positive $\left(\mathrm{WHI}^{+}\right)$ work-home interactions. It was assumed that both complementary and supplementary P-O fit and OI were positively related to $\mathrm{WHI}^{+}$and negatively to $\mathrm{WHI}^{-}$. Materials and Methods: The study was conducted on a large sample of Polish blue and white collar workers. The subjects were interviewed by means of questionnaires measuring: supplementary and complementary dimensions of P-O fit, OI and WHI. General work ability and demographic variables were also controlled in the study, and statistical analysis of ANOVA, pairwise comparison as well as regression were performed. Results: P-O fit and OI differentiated the subjects in terms of WHI. For women supplementary fit was a significant predictor of $\mathrm{WHI}^{-}$and explained $12 \%$ of its variance, for men it was complementary fit with the number of working days per week and the level of education, which explained $22 \%$ of variance. Supplementary fit and OI explained $16 \%$ of $\mathrm{WHI}^{+}$variance in women; OI, tenure at the main place of employment and the level of education explained $8 \%$ of $\mathrm{WHI}^{+}$variance in men. Conclusions: It has been proven that not only are the effects of P-O fit and OI limited to the work environment but they also permeate boundaries between work and home and influence private life - good level of P-O fit and good OI play facilitating role in the positive spillover between work and home. Gender differences in the significance and predictive values of P-O fit and OI for WHI were also found. The innovative aspect of the work is the inclusion of P-O fit and OI in the range of significant predictors of work-home interaction. The results can serve as rationale for employers that improvement of P-O fit and employees' organizational identification should be included in work-life balance programs.
\end{abstract}

Key words:

Complementary and supplementary fit, Organizational identification, Work to family spillover

\section{INTRODUCTION}

Model of social roles where public/occupational sphere was reserved for men, and family sphere for women, goes into oblivion. It has been replaced by the model of dual-career relationship where both partners work. Such situation may lead to interference between the work and family roles, which in turn can bring both negative and positive outcomes. Much research effort has been spent on tracking and analysis of adverse effects related to the conflicting requirements concerning multiple roles. It was found that certain work characteristics e.g. work time schedule, quantitative workload, mental workload, occupational stress, lack of job autonomy, lack of support from supervisor or/and coworkers [1-3] and individual

The research was conducted within the projects: IMP 21.1 "Person-organization fit as a predictor of work-home interference", project leader: Dorota Merecz, PhD; and WND-POKL.02.03.01-00-001/08 "Developing comprehensive preventive programs - prevention of psychosocial risks at work"; vice project leader: Dorota Merecz, PhD. Received: September 17, 2012. Accepted: December 8, 2013.

Corresponding author: D. Merecz, Department of Occupational Psychology, Nofer Institute of Occupational Medicine, św. Teresy 8, 91-348 Łódź, Poland (e-mail: merecz@imp.lodz.pl). 
differences - personality, values, skills, coping styles, selfevaluation as the factors which affect the relationship between work and private life [4-7] lead to difficulties in enacting private activities. In the review of Allen et al. [8] consequences of conflict between work and home were divided into 3 categories:

- work related - e.g. decrease of job satisfaction, reduction of organizational commitment, intention to turnover, absenteeism, decline of job performance, etc.;

- non-work related - decrease of life, marital, and family satisfaction, reduction of family performance;

- stress related - general psychological strain, somatic/ physical symptoms, depression, substance abuse, burnout.

For more than 10 years now, with the increasing popularity of positive psychology, researchers have been acknowledged that handling multiple roles does not necessary bring stress or overload, but can be also beneficial. It is related to spillover or transfer of skills, competences, experiences and behaviors acquired in one role to the other domain. Moods, emotions and values from one sphere can be also spread from one domain to the other [9] and such positive spillover improves the ability of meeting demands of the role from the other domain. In few studies the effects of positive work-family spillover were explored. It was found that positive work-family spillover is related to better physical and mental health [10,11], as well as to well-being at work and general well-being [12]. It also influences employees' work attitudes, e.g. workers who experience positive spillover are less motivated to change work [9].

\section{Work-Home Interaction}

Complex nature of the relationship between family and work domains and its consequences is reflected by term work-home interaction [13]. Based on Job DemandsResources Model [14] and Effort-Recovery Model [15], Bakker and Geurts [16] suggest that the possible effects of work-home interaction depend on job demands-resources ratio and possibilities for recovery after work. If job demands do not exceed resources, and there are no obstacles in recovery process, the worker should experience positive work-home interaction $\left(\mathrm{WHI}^{+}\right)$. If resources are not enough to meet job demands and/or recovery after work is incomplete, the next day the worker has to make additional compensatory efforts to cope with work demands. In longer perspective such a situation may lead to chronic load reaction and produce adverse health effects and a negative work-home interaction $\left(\mathrm{WHI}^{-}\right)$[1].

\section{Person-Organization fit}

In this paper we examine whether the work-home interaction is affected by the level of Person-Organization fit (P-O fit). Person-Organization fit is understood as a match between individuals and employing organization and is defined as a value $[17,18]$ or goal [19] congruence. It can be considered in terms of 2 dimensions - complementary and supplementary fit [20]. Complementary fit consists of 2 sub-dimensions: demands-abilities fit which is defined as a state when the individual's knowledge, skills and abilities meet environmental needs and needssupplies fit - when the individual's needs meet environmental supplies [17,21]. In turn, supplementary fit is a degree of similarity [20] which can relate to values, goals, personality traits or attitudes of the person and environment.

The concept of Person-Organization fit is a part of the Person-Environment fit theory, which says, that congruence between the individual and the environment has a profound effect on well-being and human functioning in work environment [22]. P-O fit is prerequisite for maintaining well-being at work thanks to its effect on satisfaction, self-esteem, sense of belonging, usefulness and employees' identity [18,22-24]. If we take it and the spillover effect into consideration [25], we find ourselves justified to presume that the level of P-O fit may enhance positive 
work-home interaction and P-O misfit may intensify negative work-home interaction.

\section{Organizational identification}

Organizational identification, the last variable from the proposed theoretical model, is the concept that has been presented in organizational studies literature since $60 \mathrm{~s}$ of the XX century. Based on the social identification theory $[26,27]$ organizational identification can be defined as a form of social identification based on the sense of belonging to an organization as a social group [28,29]. It is rooted in the cognitive process based on perceived similarities with the members of organization and dissimilarities with the members of other organization. Employees selfcategorize organizational membership in order to reduce the level of subjective uncertainty and to gain positive distinctiveness. Humans, as social beings, pay very much attention to social ties which are developed and maintained on the basis of perceived similarity between the individual and other people. Thanks to the social identification process, people experience basic psychological comfortfulfilling affiliation and security needs and thus they gain sense of existence in a social world and make their effort meaningful.

\section{Work-Family fit}

Searching for the relationships between theoretical constructs of Work-Home Interaction and Person-Organization fit is fully justified. Until recently, PersonEnvironment fit model was mainly used to study the relationship between an employee/candidate for work and work environment, somehow ignoring the fact that everyone undertakes a variety of social roles. Since the 90s it has been successfully used in explaining human functioning in the broader context of professional and private life. It has evolved into the concept of Work-Family fit which corresponds to the concept of Work-Life Balance. Extending the scope of insight into the P-E fit issue by the aspect of personal and family life is indeed reasonable. Definitions of work-family fit are based on the concepts known from research on work-life balance. Grzywacz and Bass [11] used it in explaining human functioning in the broader context of work and family as a combination of conflict and facilitation between work and home. A more recent course in the study of this issue is set by Voydanoff [30] who models the relationship between fit and balance where the fit is the cause and balance is the effect. This approach is the closest to the authors' reasoning and it sets the direction of research hypotheses in this study. The approach of Person-Environment fit paradigm is suitable for describing the consequences of stress and lack of balance between work and private life for 2 reasons. Firstly, because processes of exchanging, strengthening and resource draining occur between professional and private spheres, which is characteristic to demandsabilities dimension of complementary fit. The second reason is that it can take into account the individual's needs, preferences and capabilities to cope with the requirements of professional and family roles, which, in turn, are the components of the needs-supplies subdimension of complementary fit.

Work-family fit comprehended this way and work-family balance open a vast field of research on the causes of adaptive and maladaptive functioning in both areas and the reasons for such a state.

\section{Gender effect on work-home interaction and person-organization fit}

Findings concerning differences in the quality of workfamily interaction are inconsistent [31]. When arguing the differences between men and women, it is always important to pay attention to the controlled variables in the study. The perceived quality of work-family interaction is affected by many factors. In the majority of research simplified models with limited number of variables are 
usually tested. Therefore, each research captures only a part of this phenomenon. Capturing the complexity of the phenomenon still constitutes a great challenge for researchers. So far, many of them have reported that women experience more negative work-home interaction (conflict) than men [e.g. 32]. It is also pointed that for women combining work, especially highly demanding, with family responsibilities has many negative consequences such as e.g. burnout. In the case of women, attempting to strike a balance is a special challenge which drains a significant amount of their resources [33]. On the other hand, there is also some evidence that men and women do not differ significantly in terms of work-family conflict (interaction) but they differ in terms of perception of work-life balance $[34,35]$.

The fit between the person and environment is recognized on many levels and in terms of its various consequences such as - attitudes, organizational commitment, mental physical well-being, and performance [36]. The perspective of gender differences, however, is not directly undertaken in research. Nevertheless, research concerning the issue of the relationship between P-O fit, the status in the organization, commitment and gender showed no direct relationship between the level of fit and gender of the respondents [37]. Research on the differences between men and women in terms of experienced work-home balance as well as P-O fit is doomed to failure. The fit is determined by too many factors related to job and work environment characteristics as well as organizational culture - when not taken into account, they may lead to wrong conclusions. Our work may be a contribution to recognition of this issue. We can only hypothesize, e.g. it is not possible for women to have a reduced ability to adapt to their work environment. Worse fit may be caused by factors beyond their control, such as the "glass ceiling" barrier preventing them from pursuing their potential and having a job meeting their standards.

\section{Aim of the study}

Although a lot of studies on the sources and consequences of WHI (especially its negative aspects) have been already carried out, there is still space for exploration of various facets of this phenomenon. Our proposal is to have a look into the relationship between $\mathrm{WHI}^{-}, \mathrm{WHI}^{+}$, Person-Organization fit (P-O fit) and organizational identification (OI). Another point of our interest with regard to antecedents of WHI is identification with an organization as a social group. To the best of our knowledge these relationships have not been recognized yet.

We have set the following hypothesis: complementary P-O fit is positively related to $\mathrm{WHI}^{+}$and negatively related to $\mathrm{WHI}^{-}$. At this stage it is hard to develop a directional hypothesis with regard to the supplementary fit and organizational identification. In general, employees' supplementary fit and organizational identification should be positively related to $\mathrm{WHI}^{+}$. On the other hand, when being a member of an organization is highly rewarding for the workers and when identity of employees is deeply rooted in the sense of belonging and commitment to the organization, they may tend to sacrifice they private life for work.

In terms of gender, we hypothesize that there will be no differences in the level of complementary and supplementary fit and organizational identification between men and women. However, there will be differences in predictors of the quality of work-home interaction.

\section{MATERIAL AND METHODS}

\section{Participants}

Data have been gathered in a random group of 600 Polish employees, city dwellers, aged from 19 to 65 years. The sample was representative for occupationally active population of citizens in terms of gender, age and city size. The following exclusion criteria were employed in the sampling procedure: being on a parental leave, receiving 
disability payment or pension; being a full-time student. Data were collected at the respondents' homes. Women accounted for $52.5 \%$ of the group and men for the remaining $47.5 \%$. The mean age for men was $39.28(\mathrm{SD}=11.06)$ and for women - 39.65 (SD = 11.04). People with vocational education were mostly men, whilst with higher education women. There were no significant differences in terms of gender in the groups with primary and secondary education. Mean tenure at the main place of employment was: for men - 10.25 (SD = 9.948) and for women - 8.88 $(\mathrm{SD}=8.92)$. The average number of working days was: $5.31(\mathrm{SD}=0.68)$ and $5.18(\mathrm{SD}=0.68)$ respectively.

\section{Measures}

The following questionnaires were employed in the study. Person-Organization Fit Questionnaire by CzarnotaBojarska [38] - to assess the level of subjective P-O fit. It consists of 3 scales - supplementary fit, complementary fit and OI. The higher the score, the better the P-O fit. An example of a statement from the complementary fit scale: "It is required from me as much as I can give"; for supplementary fit: "I fit to my organization" and for organizational identification scale: "I believe that the organization is important to me". The respondents' answers were collected on a 6-point scale (from 0 - strongly disagree to 5 strongly agree). As the subscales of P-O fit Questionnaire differ in terms of items number, in order to make them comparable, subscale scores were recalculated to the mean for the item in each subscale. Cronbach $\alpha$ coefficients for complementary, supplementary and identification subscales were high (respectively 0.94, 0.96 and 0.86). To assess positive and negative work home interactions 2 subscales of Survey Work-Home Interaction Nijmegen (SWING) [13,39] were used: (a) a negative influence of work on private life $\left(\mathrm{WHI}^{-}\right)$, (b) a positive influence of work on private life $\left(\mathrm{WHI}^{+}\right)$. The higher the score of the respondent, the higher the level of positive or negative interaction experienced by him/her in the given subscale. Psychometric properties of Polish adaptation of SWING are comparable to these obtained by Nijmegen's research group. Selected items from each subscale are: "You are irritable at home because your work is demanding"; "You find it difficult to fulfill your domestic obligations because you are constantly thinking about your work" and "After spending a pleasant weekend with your spouse/family/friends, you have more fun in your job" or "You fulfill your domestic obligations better because of things you have learned on your job". The respondents' answers were collected on a 4-point scale (from 0 - never to 3 - always). The indicators of interactions were the means calculated from the items of each scale. Cronbach $\alpha$ coefficients for the $\mathrm{WHI}^{-}$and $\mathrm{WHI}^{+}$ were 0.89 and 0.73 respectively.

\section{STATISTICAL ANALYSIS}

Statistical analysis was performed with SPSS.19 for Windows. Non-parametric Kruskal-Wallis and Mann-Whitney tests were used to estimate the significance of range differences in $\mathrm{WHI}^{-}$and $\mathrm{WHI}^{+}$between the groups of respondents with different levels of P-O fit. The stepwise regression analysis (forward) was performed in order to check the predictive value of $\mathrm{P}-\mathrm{O}$ fit, $\mathrm{OI}$ and demographic characteristics for estimation of $\mathrm{WHI}^{-}$and $\mathrm{WHI}^{+}$. Additionally, two-way ANOVA in design $2 \times 3$ was used to investigate interaction effects of gender, P-O fit and OI on the level of $\mathrm{WHI}^{-}$and $\mathrm{WHI}^{+}$. Being aware of already found antecedents of WHI [4], while testing the predictive value of $\mathrm{P}-\mathrm{O}$ fit dimensions and organizational identification for positive and negative WHI in regression models, we also included other variables in the analysis. These variables were: age, level of education, number of working days per week, and tenure at the main place of employment as well as general work ability. General work ability was measured with a single question taken from the Polish adaptation [40] of Work Ability Index [41]. 


\section{RESULTS}

The comparison of men and women in Person-Organization fit and WHI indices showed no significant differences. In order to compare the level of $\mathrm{WHI}^{-}$and $\mathrm{WHI}^{+}$, the scores in the scales of P-O fit questionnaire were divided into 3 groups - low, medium and high: range of low scores from the minimum value to the mean value minus $0.5 \mathrm{SD}$; range of mean scores - from the mean value minus $0.49 \mathrm{SD}$ to mean value plus $0.49 \mathrm{SD}$; range of high scores - from the mean value plus $0.5 \mathrm{SD}$ to the maximum value.

Descriptive statistics of P-O fit, $\mathrm{OI}$ and $\mathrm{WHI}$ are presented in Tables 1 and 2.

The results of non-parametric ANOVA and pairwise comparison between the groups showed significant differences in the level of $\mathrm{WHI}^{-}$. For complementary fit it was $H_{(2, \mathrm{~N}=600)}=58.097, \mathrm{p}<0.001$; for supplementary fit $H_{(2, \mathrm{~N}=600)}=49.866, \mathrm{p}<0.001$; and for OI
$H_{(2, \mathrm{~N}=600)}=28.806, \mathrm{p}<0.001$. ANOVA analysis also showed significant differences in the level of $\mathrm{WHI}^{+}$. For complementary fit it was $H_{(2, \mathrm{~N}=600)}=37.048, \mathrm{p}<0.001$; for supplementary fit $H_{(2, \mathrm{~N}=600)}=41.788, \mathrm{p}<0.001$ and for OI $H_{(2, \mathrm{~N}=600)}=45.437, \mathrm{p}<0.001$.

Results of the pairwise comparison for sub-dimensions of P-O fit, OI and $\mathrm{WHI}^{-}$are shown on Figure 1 and described below.

The level of $\mathrm{WHI}^{-}$was significantly the highest in the people who obtained low levels of complementary and supplementary fit, while the lowest $\mathrm{WHI}^{-}$was experienced by those who reached high levels of complementary and supplementary fit. Organizational identification also differentiated our respondents. The people who identified themselves with their organizations in the slightest degree experienced significantly higher level of $\mathrm{WHI}^{-}$in comparison with those with medium and strong OI.

Table 1. Descriptive statistic for Person-Organization (P-O) fit and organizational identification (OI)

\begin{tabular}{|c|c|c|c|c|c|c|c|c|c|c|}
\hline \multirow{2}{*}{ Parameters } & \multicolumn{5}{|c|}{$\begin{array}{c}\text { Men } \\
(\mathrm{N}=285) \\
\end{array}$} & \multicolumn{5}{|c|}{$\begin{array}{c}\text { Women } \\
(\mathrm{N}=315)\end{array}$} \\
\hline & $\min$. & $\max$ & M & SD & $\begin{array}{l}\text { average } \\
\text { range }\end{array}$ & $\min$. & $\max$ & M & $\mathrm{SD}$ & $\begin{array}{l}\text { average } \\
\text { range }\end{array}$ \\
\hline Complementary fit & 1.00 & 4.94 & 3.29 & 0.72 & 313.59 & 0.15 & 4.92 & 3.17 & 0.77 & 288.66 \\
\hline Supplementary fit & 1.61 & 4.94 & 3.72 & 0.57 & 306.15 & 1.06 & 4.94 & 3.68 & 0.59 & 295.38 \\
\hline $\begin{array}{l}\text { Organizational } \\
\text { identification }\end{array}$ & 0.54 & 4.77 & 3.28 & 0.71 & 312.95 & 0.94 & 5.00 & 3.20 & 0.75 & 289.24 \\
\hline
\end{tabular}

min. - minimum; max - maximum.

$\mathrm{M}$ - mean; SD - standard deviation.

Table 2. Descriptive statistic for the positive and negative work home influence, and work ability

\begin{tabular}{|c|c|c|c|c|c|c|c|c|c|c|}
\hline \multirow{2}{*}{ Parameters } & \multicolumn{5}{|c|}{$\begin{array}{c}\text { Men } \\
(\mathrm{N}=285)\end{array}$} & \multicolumn{5}{|c|}{$\begin{array}{c}\text { Women } \\
(\mathrm{N}=315)\end{array}$} \\
\hline & $\min$. & $\max$ & $\mathrm{M}$ & SD & $\begin{array}{l}\text { average } \\
\text { range }\end{array}$ & $\min$ & $\max$ & M & SD & $\begin{array}{c}\text { average } \\
\text { range }\end{array}$ \\
\hline $\mathrm{WHI}^{-}$ & 0 & 17 & 5.53 & 4.210 & 306.51 & 0 & 23 & 5.43 & 4.650 & 291.05 \\
\hline $\mathrm{WHI}^{+}$ & 0 & 15 & 5.71 & 2.840 & 295.06 & 0 & 15 & 6.13 & 3.160 & 309.05 \\
\hline Work ability & 1 & 10 & 7.98 & 1.855 & 297.02 & 0 & 10 & 7.99 & 1.915 & 299.85 \\
\hline
\end{tabular}

$\mathrm{WHI}^{-}$- negative work-home interaction; $\mathrm{WHI}^{+}$- positive work-home interaction.

Other abbreviations as in Table 1. 


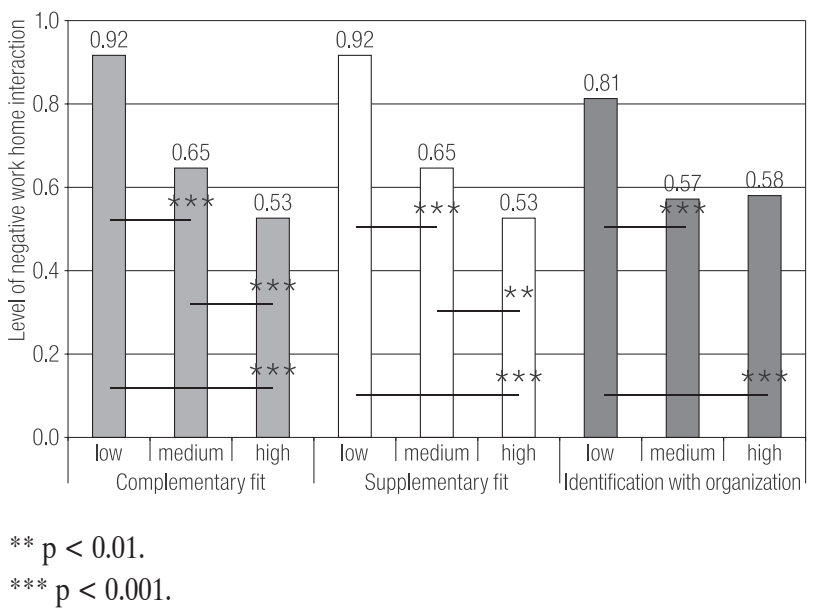

Fig. 1. Differences in the levels of negative work-home interaction $\left(\mathrm{WHI}^{-}\right)$between the groups of different levels of PersonOrganization (P-O) fit and organizational identification (OI)

As regards the level of $\mathrm{WHI}^{+}$, for complementary and supplementary fit the results may be interpreted "in the mirror image" (Figure 2). $\mathrm{WHI}^{+}$was significantly the highest in the people who obtained high levels of complementary and supplementary fit, whilst the lowest $\mathrm{WHI}^{+}$was experienced by those who reached the lowest levels of complementary and supplementary fit.

Again, OI differentiated all groups in terms of $\mathrm{WHI}^{+}$(Figure 2). The people who identified themselves with an organization the least experienced significantly lower level of $\mathrm{WHI}^{+}$than those with medium level of identification,

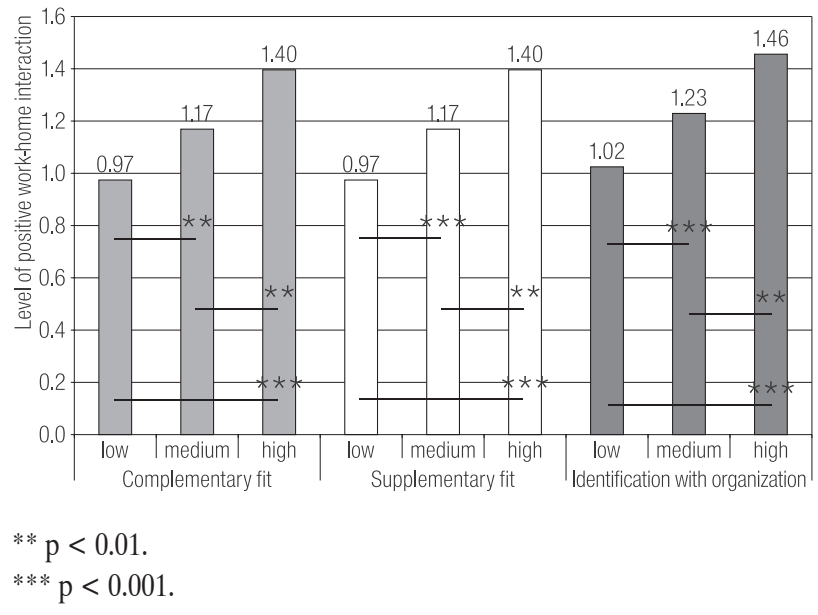

Fig. 2. Differences in the levels of positive work-home interaction $\left(\mathrm{WHI}^{+}\right.$) between the groups of different levels of PersonOrganization (P-O) fit and organizational identification (OI)

who in turn, had significantly lower level of $\mathrm{WHI}^{+}$than those with strong OI.

The predictive values of P-O fit sub-dimensions and OI for work-home interaction were tested using regression models. We have presumed, that gender is a moderator of work-family interference [35] and for this reason, regression analyses were performed separately for men and women. The results are shown in Tables 3 and 4.

Taking into account $\mathrm{WHI}^{-}$, we obtained interesting results as regards differences related to gender. In the case of women, supplementary fit was the only significant

Table 3. Significant predictors of $\mathrm{WHI}^{-}$for men and women - results of the stepwise regression analysis

\begin{tabular}{clccccc}
\hline Step & \multicolumn{1}{c}{ Entered variable } & $\mathrm{R}^{2}$ & $\Delta$ of adjusted $\mathrm{R}^{2}$ & df & F-ratio & $\beta$ \\
\hline Men & & & & & & \\
1 & complementary fit & 0.152 & - & 277 & $49.790^{* * *}$ & $-0.363^{* * *}$ \\
2 & number of working days per week & 0.199 & 0.047 & 276 & $15.994^{* * *}$ & $0.209^{* * *}$ \\
3 & level of education & 0.218 & 0.019 & 275 & $6.659^{* *}$ & $0.138^{* *}$ \\
Women & & & & & & \\
1 & supplementary fit & 0.123 & - & 305 & $42.940^{* * *}$ & $-0.351^{* * *}$ \\
\hline
\end{tabular}

${ }^{a}$ Excluded variables: men - work ability, supplementary fit, OI, tenure at main place of employment; women - work ability, OI, level of education, tenure at main place of employment, number of working days per week, complementary fit.

Adjusted $\mathrm{R}^{2}$ - explained variance; $\Delta$ of adjusted $\mathrm{R}^{2}$ - change in explained variance; df - degrees of freedom; $\beta$ - standardized regression coefficient. $* p<0.05$.

${ }^{* *} \mathrm{p}<0.01$.

*** $\mathrm{p}<0.001$. 
Table 4. Significant predictors of $\mathrm{WHI}^{+}$for men and women - results of the stepwise regression analysis

\begin{tabular}{clccccc}
\hline Step & \multicolumn{1}{c}{ Entered variable } & Adjusted $\mathrm{R}^{2}$ & $\Delta$ of adjusted $\mathrm{R}^{2}$ & $\mathrm{df}$ & F-ratio & $\beta$ \\
\hline Men & & & & & & \\
1 & organizational identification & 0.050 & - & 277 & $14.490^{* * *}$ & $0.189^{* *}$ \\
2 & tenure at the main place of employment & 0.064 & 0.014 & 276 & $4.173^{*}$ & $0.140^{* *}$ \\
3 & level of education & 0.082 & 0.018 & 275 & $5.370^{* *}$ & $0.135^{*}$ \\
Women & & & & & & \\
1 & organizational identification & 0.155 & - & 305 & $56.071^{* * *}$ & $0.262^{* * *}$ \\
2 & supplementary fit & 0.163 & 0.008 & 304 & $4.743^{*}$ & $0.174^{*}$ \\
\hline
\end{tabular}

${ }^{a}$ Excluded variables: men - work ability, complementary fit, supplementary fit, number of working days per week; women - work ability, complementary fit, supplementary fit, tenure at the main place of employment, number of working days per week.

Abbreviations as in Table 3.

predictor of $\mathrm{WHI}^{-}$, which explained $12 \%$ of its variance. The lower was the level of supplementary fit to an organization, the higher was the level of experiencing $\mathrm{WHI}^{-}$. In the case of men, the studied relationship turned out to be more complex. Complementary fit was the strongest predictor of $\mathrm{WHI}^{-}$and explained alone the highest percentage of variance $-15 \%$. There were other significant factors such as: number of working days per week and level of education. Together, all these predictors explained $22 \%$ of $\mathrm{WHI}^{-}$variance. The lower the level of complementary fit, the greater the number of working days per week, and the higher the level of education and thus, the higher the level of $\mathrm{WHI}^{-}$experienced by men.

Organizational identification was a significant predictor of $\mathrm{WHI}^{+}$both, in the case of men and women. The direction of this relationship was also the same: the high level of OI was related to the high level of $\mathrm{WHI}^{+}$, but there were differences in the percentage of variance $(5 \%$ for men and $15 \%$ for women) and in the strength of the relationship $(\beta=0.189 ; p<0.001$ and $\beta=0.262 ; p<0.001$ respectively). Additionally, men who had longer tenure at the main place of employment and a higher level of education reported higher $\mathrm{WHI}^{+}$. Together, these 3 variables with OI explained $8 \%$ of variance. In the group of women, also supplementary fit was a significant predictor of $\mathrm{WHI}^{+}$, which means that a higher level of OI combined with a high level of supplementary fit gave the best results for $\mathrm{WHI}^{+}$. Age and work ability have proven to be significant predictors neither of $\mathrm{WHI}^{-}$nor of $\mathrm{WHI}^{+}$.

The interactive effects of gender, dimensions of P-O fit and $\mathrm{OI}$ on $\mathrm{WHI}^{+}$and $\mathrm{WHI}^{-}$were tested by means of twoway ANOVA.

Only interaction effect of gender and level of OI turned out to be significant (Figure 3) $F_{(2,594)}=2.594 ; \mathrm{p}=0.028$ $\left(\eta^{2}=0.012\right)$, and only one difference between the groups remained significant $(\mathrm{p}=0.002)$ after post hoc analysis women who had a high level of OI experienced a higher level of positive work-home interaction than men who had a similar level of OI.

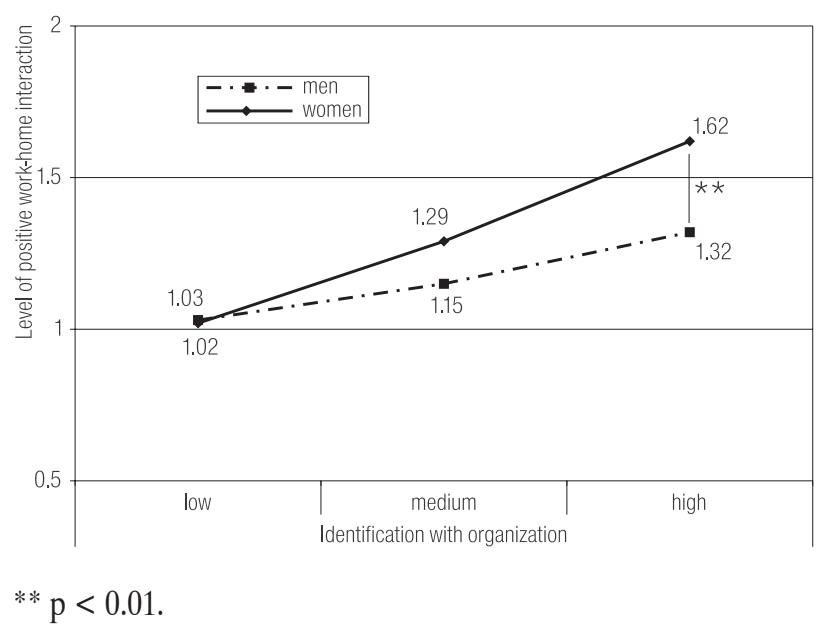

Fig. 3. Result of the two-way ANOVA estimation of gender and organizational identification (OI) on the level of positive work-home interaction $\left(\mathrm{WHI}^{+}\right)$ 


\section{DISCUSSION}

The general aim of the study was to explore the relationships between complementary and supplementary Person-Organization fit, organizational identification and work-home interaction. Our study showed that the notion that performing many roles leads to stressful overload is too simplistic. Instead of thinking about harmfulness of performing multiple roles, we should rather look for facilitators of successful coping with the demands of performing multiple roles. In the light of the obtained results, $\mathrm{P}-\mathrm{O}$ fit and $\mathrm{OI}$ seem to have a significant role in decreasing negative WHI and strengthening positive WHI. Previous research has indicated, that demands of occupational and private/family life are connected with the level of conflict between work and home, whilst resources of those 2 spheres - with positive spillover [1].

As we mentioned above, there were reasons to consider the issue of WHI from separate perspectives for men and women, as experiencing and coping with its negative aspect is, to some extent, gender determined $[4,34,42]$. Although comparison of the levels of experienced $\mathrm{WHI}^{-}$and $\mathrm{WHI}^{+}$ between genders did not show any significant differences between men and women in the studied sample, such differences were found to have significance and predictive value of assumed determinants of $\mathrm{WHI}^{+}$and $\mathrm{WHI}^{-}$. In women, both organizational identification as well as supplementary fit were significant predictors of $\mathrm{WHI}^{+}$. These constructs are the 2 main regulators of behavior at work [43]. Supplementary fit is the resource which positively affects well-being and facilitates social support [44]. It also promotes organizational identification, which in turn is associated with organization citizenship behaviors, loyalty, productivity and performance [43]. We assume that these behaviors are responsible for the sense of emotional well-being at work, which can be transferred into the private sphere. In the case of men only OI, education and job tenure at the main place of employment were significant predictors of $\mathrm{WHI}^{+}$. It means that well educated men who reached a stable position in an organization and identified themselves with the organization as the whole experience beneficial influence of work on private life activities.

In our study, complementary fit proved to be an important predictor of $\mathrm{WHI}^{-}$for men, and supplementary fit for women. These differences may be rooted in the value priorities of women and men. Schwartz and Rubel [45] found that such values as power, stimulation, hedonism, achievement and self-direction are preferred by men, while benevolence and universalism take a higher rank in women's hierarchy of values. For men, complementary fit which reflects a good ratio between efforts, skills and rewards is an important condition to feel good at work, have a sense of personal accomplishment and self-efficacy. Thus, good complementary fit is a positive experience of satisfying important needs, strengthening men's self-confidence which can be transferred into their private lives. For women, gaining a good level of supplementary fit is the way of fruition of their core values in occupational setting, the way to fulfill the need for affiliation. The sense of belonging and community have beneficial effect for women's well-being. Positive emotional experiences resulting from interpersonal relations at work seem to bear fruits in private life functioning. We assume that complementary fit in men and supplementary fit in women are resources which help to reduce negative effect of work on private life.

However, it is worth to underline that we still do not know much about gender related differences in the effects of different dimensions of $\mathrm{P}-\mathrm{O}$ on individuals' functioning and this issue needs further research aimed at unraveling the relationship between gender, $\mathrm{P}-\mathrm{O}$ fit and the outcomes like e.g. work-life balance, life satisfaction and well-being. As it has been suggested by Demerouti et al. [46], there is also a need to study the dynamics of these relationships which may depend on life and career stage demands and resources. Our results support the statement, that P-O fit is a significant predictor of the quality of work-life interaction, but it 
is important to emphasize that different aspects of fit affect the balance between work and family domains in men and women. Optimal P-O fit can be treated as a resource which helps to maintain positive work-home interaction and facilitate positive transfer of benefits from the work environment to the family environment.

In the light of the presented results, P-O fit and OI seem to be important factors affecting not only behaviors, attitudes at work but also influencing people's functioning in private life.

The innovative aspect of the work is the inclusion of $\mathrm{P}-\mathrm{O}$ fit and $\mathrm{OI}$ in the range of significant predictors of work-home interaction.

\section{Strengths and Limitations}

A great advantage of the study is exploration of the role of P-O fit and organizational identification as factors which have a potential for facilitating positive work-home interaction and reducing negative WHI. The study was performed in the large sample of Polish employees representing various occupations - blue and white-collar workers - which makes the obtained results more universal.

The limitation of the study is its cross-sectional design which does not allow for drawing cause-effect conclusions.

\section{CONCLUSION}

The presented study contributes to expanding the knowledge in the area of Person-Organization fit and Workhome interaction by connecting those 2 constructs and examining relationships between them. According to our results, promoting P-O fit and organizational identification is beneficial not only for the organization itself but also for the employees' families and can be seen as an important part of work life balance programs developed at the organizational level. Developing organizational strategy for maintaining the optimal level of P-O fit can improve both working and family life quality. The results of the study can serve as a guidepost for entrepreneurs and managerial staff wishing to strengthen competitiveness of their business and at the same time realize the ideas of corporate social responsibility.

\section{REFERENCES}

1. Demerouti E, Bakker AB, Bulters AJ. The loss spiral of work pressure, work-home interference and exhaustion: Reciprocal relations in a three-wave study. J Vocat Behav. 2004;64(1):131-49, http://dx.doi.org/10.1016/S0001-8791(03) 00030-7.

2. Geurts S, Rutte C, Peeters M. Antecedents and consequences of work-home interference among medical residents. Soc Sci Med. 1999;48(9):1135-48, http://dx.doi.org/10.1016/S02779536(98)00425-0.

3. Frone MR, Yardley JK, Markel KS. Developing and testing an integrative model of the work-family interface. J Vocat Behav. 1997;50(2):145-67, http://dx.doi.org/10.1006/ jvbe.1996.1577.

4. Byron K. A meta-analytic review of work-family conflict and its antecedents. J Vocat Behav. 2005;67(2):169-98, http:// dx.doi.org/10.1016/j.jvb.2004.08.009.

5. Beauregard TA. Predicting interference between work and home: A comparison of dispositional and situational antecedents. J Manag Psych. 2006;21(3):244-64, http://dx.doi. org/10.1108/02683940610659588.

6. Bekker MH, Willemse JJ, de Goeij JW. The role of individual differences in particular autonomy-connectedness in women's and men's work-family balance. Women Health. 2010;50(3):241-61, http://dx.doi.org/10.1080/036302 42.2010.480902.

7. Friede A, Ryan AM. The importance of the individual: how selfevaluations influence the work-family interface. In: Kossek EE, Lambert SJ, editors. Work and life integration: Organizational, cultural, and individual perspectives LEA's organization and management series. Mahwah, New York: Lawrence Erlbaum Associates Publishers; 2005. p. 193-209. 
8. Allen TD, Herst DEL, Bruck CS, Sutton M. Consequences associated with work-to-family conflict: A review and agenda for future research. J Occup Health Psychol. 2000;5(2):278308, http://dx.doi.org/10.1037/1076-8998.5.2.278.

9. Haar JM, Bardoel EA. Positive spillover from the workfamily interface: A study of Australian employees. Asia Pac J Human Resour. 2008;46(3):275-87, http://dx.doi. org/10.1177/1038411108095759.

10. Grzywacz JG. Work-family spillover and health during midlife: is managing conflict everything? Am J Health Promot. 2000;14(4):236-43, http://dx.doi.org/10.4278/08901171-14.4.236.

11. Grzywacz JG, Bass BL. Work, family, and mental health: testing different models of work family fit. J Marr Fam. 2003;65(1):248-61, http://dx.doi.org/10.1111/j.17413737.2003.00248.x.

12. Kinnunen U, Feldt T, Geurts S, Pulkkinen L. Types of workfamily interface: Well-being correlates of negative and positive spillover between work and family. Scand J Psychol. 2006;47(2):149-62, http://dx.doi.org/10.1111/j.14679450.2006.00502.x.

13. Geurts S, Taris T, Kompier M, Dikkers J, van Hooff M, Kinnunen $\mathrm{U}$. Work-home interaction from a work psychological perspective: Development and validation of a new questionnaire, the SWING. Work Stress. 2005;19(4):319-39, http:// dx.doi.org/10.1080/02678370500410208.

14. Bakker AB, Demerouti E, de Boer E, Schaufeli WB. Job demands and job resources as predictors of absence duration and frequency. J Vocat Behav. 2003;62(2):341-56, http:// dx.doi.org/10.1016/S0001-8791(02)00030-1.

15. Meijman TF, Mulder G. Psychological aspects of workload. In: Drenth PJD, Thierry H, de Wolff ChJ, editors. Handbook of work and organizational psychology. Vol. 2. Work psychology. Hove: Psychology Press/Erlbaum; 1998. p. 5-33.

16. Bakker AB, Geurts SAE. Toward a dual-process model of work-home interference. Work Occup. 2004;31(3):345-66, http://dx.doi.org/10.1177/0730888404266349.
17. Kristof AL. Person-organization fit: An integrative review of its conceptualizations, measurement, and implications. Person Psych. 1996;49(1):1-49, http://dx.doi. org/10.1111/j.1744-6570.1996.tb01790.x.

18. Hoffman BJ, Woehr DJ. A quantitative review of the relationship between person-organization fit and behavioral outcomes. J Vocat Behav. 2006;68(3):389-99, http://dx.doi. org/10.1016/j.jpb.2005.08.003.

19. Vancouver JB, Schmitt NW. An exploratory examination of Person-Organization fit. Organizational goal congruence. Person Psych. 1991;44(2):333-52, http://dx.doi. org/10.1111/j.1744-6570.1991.tb00962.x.

20. Cable DM, Edwards JR. Complementary and supplementary fit.: A theoretical and empirical integration. J Appl Psychol. 2004;89(5):822-33, http://dx.doi.org/10.1037/00219010.89.5.822.

21. Edwards JR. Person-job fit: A conceptual integration, literature review, and methodological critique. In: Cooper CL, Robertson IT, editors. International review of industrial and organizational psychology. Vol. 6. Oxford, England: John Wiley \& Sons; 1991. p. 283-357.

22. Edwards JR, Rothbard NP. Mechanisms linking work and family: Clarifying the relationship between work and family constructs. Acad Manage Rev. 2000;25(1):178-99, http:// dx.doi.org/10.5465/AMR.2000.2791609.

23. Amos EA, Weathington BL. An analysis of the relation between employee - organization value congruence and employee attitudes. J Psychol. 2008;142(6):615-32, http:// dx.doi.org/10.3200/JRLP.142.6.615-632.

24. Verquer ML, Beehr TA, Wagner SH. A meta-analysis of relations between person-organization fit and work attitudes. J Vocat Behav. 2003;63(3):473-89, http://dx.doi.org/10.1016/ S0001-8791(02)00036-2.

25. Chen Z, Powell GN, Greenhaus JH. Work-to-family conflict, positive spillover, and boundary management: A personenvironment fit approach. J Vocat Behav. 2009;74(1):82-93, http://dx.doi.org/10.1016/j.jvb.2008.10.009. 
26. Turner JC. Social categorization and the self-concept: A social cognitive theory of group behavior. In: Lawler EJ, editor. Advances in group processes: theory and research. Vol. 2. Greenwich, CT: JAI Press; 1985. p. 77-122.

27. Ashforth BE, Mael FA. Social identity theory and the organization. Acad Manage Rev. 1989;14(1):20-39, http://dx.doi. org/10.5465/AMR.1989.4278999.

28. Grice T, Paulsen N, Jones L. Multiple targets of organizational identification: The role of identification congruency. JASHN. 2002;1(2):22-31.

29. Boroş S. Organizational identification: Theoretical and empirical analyses of competing conceptualizations. Cogn Crei Comp/Cogn Brain Behav. 2008;XII(1):1-27.

30. Voydanoff P. Toward a conceptualization of perceived workfamily fit and balance: A demands and resources approach. J Marr Fam. 2005;67(4):822-36, http://dx.doi.org/10.1111/ j.1741-3737.2005.00178.x.

31. Eby LT, Casper WJ, Lockwood A, Bordeaux C, Brinley A. Work and family research in OI/OB: Content analysis and review of the literature (1980-2002). J Vocat Behav. 2005;66(1):124-97, http://dx.doi.org/10.1016/ j.jvb.2003.11.003.

32. Dyrbye LN, Shanafelt TD, Balch CM, Satele D, Sloan J, Freischlag J. Relationship between work-home conflicts and burnout among American surgeons: A comparison by sex. Arch Surg. 2011;146(2):211-7, http://dx.doi.org/10.1001/ archsurg.2010.310.

33. Langballe EM, Innstrand ST, Aasland OG, Falkum E. The predictive value of individual factors, work-related factors, and work-home interaction on burnout in female and male physicians: A longitudinal study. Stress Health. 2011;27(1):73-87, http://dx.doi.org/10.1002/ smi.1321.

34. Duxbury LE, Higgins CA. Gender differences in work-family conflict. J Appl Psychol. 1991;76(1):60-74, http://dx.doi. org/10.1037/0021-9010.76.1.60.

35. Keene JR, Quadagno J. Predictors of perceived workfamily balance: Gender difference or gender similarity?
Sociol Perspect. 2004;47(1):1-23, http://dx.doi.org/10.1525/ sop.2004.47.1.1.

36. Edwards JR, Shipp AJ. The relationship between person-environment fit and outcomes: An integrative theoretical framework. In: Ostroff C, Judge TA, editors. Perspectives on organizational fit. San Francisco: Jossey-Bass; 2007. p. 209-58.

37. Seong JY, Hong DS, Park WW. Work status, gender, and organizational commitment among Korean workers: The mediating role of person-organization fit. Asia Pac J Manage. 2012;29(4): 1105-29, http://dx.doi.org/10.1007/s10490-011-9248-6.

38. Czarnota-Bojarska J. [The questionnaire for the measurement of subjective Person-Organization fit]. Psych Eduk Spol. 2006;3(2):151-63. Polish.

39. Mościcka-Teske A, Merecz-Kot D. [Polish adaptation of SWING questionnare (Survey Work-Home Interaction Nijmegen)]. Med Pr. 2012;63(3):355-69. Polish.

40. Pokorski J. [Work Ability Index - Polish version]. Kraków: Uniwersytet Jagielloński; 1998. Polish.

41. Tuomi K, Ilmarinen J, Jahkola A, Katajarinne L, Tulkki A. Work Ability Index. Helsinki: Finnish Institute of Occupational Health; 1998.

42. Loscocco KA. Work-family linkages among self-employed women and men. J Vocat Behav. 1997;50(2):204-26, http:/ dx.doi.org/10.1006/jvbe.1996.1576.

43. Czarnota-Bojarska J. [Person-Organization fit and organizational identity]. Warszawa: Wydawnictwo Naukowe SCHOLAR; 2010. Polish.

44. House JS, Landis KR, Umberson D. Social relationships and health. Science. 1988;241(4865):540-5, http://dx.doi. org/10.1126/science.3399889.

45. Schwartz SH, Rubel T. Sex differences in value priorities: Cross-cultural and multimethod studies. J Pers Soc Psychol. 2005;89(6):1010-28, http://dx.doi.org/10.1037/00223514.89.6.1010.

46. Demerouti EM, Peeters CW, van der Heijden B. Work-family interface from a life and career stage perspective: The role of demands and resources. Int J Psych. 2012;47(4):241-58, http://dx.doi.org/10.1080/00207594.2012.699055.

This work is available in Open Access model and licensed under a Creative Commons Attribution-NonCommercial 3.0 Poland License - http://creativecommons.org/ licenses/by-nc/3.0/pl/deed.en. 